\title{
Enfoque de gênero e relação saúde/trabalho no contexto de reestruturação produtiva e precarização do trabalho
}

\author{
Gender focus and the relationship between \\ health and work in the context of productive \\ reorganization and underemployment
}

\footnotetext{
1 Centro de Estudos da Saúde do Trabalhador e Ecologia Humana, Escola Nacional de Saúde Pública, Fundação Oswaldo Cruz. Rua Leopoldo Bul hões 1480, Rio de Janeiro, RJ 21045-900, Brasil.
}

Abstract This article analyzes the issue of workers' health in the context of productive reorganization, based on the sexual division of labor and gender relations. The author begins with a discussion of cross-cutting issues and moves on to analyze current trends: the increase in female labor, its incorporation by multinational companies in the so-called Third World countries, an increase in differences and greater vulnerability vis-à-vis the process invol ving underemployment and suspension of social labor clauses. Finally, two examples of female labor (in industry and the school system) foster reflection on the effect of productive reorganization on working women's health, highlighting the issue of excessi ve workloads for women.

Key words Female Labor; Women's Health; Occupational Health; Gender Relations

Resumo Neste artigo procura-se analisar a questão da saúde dos(as) trabalhadores(as) frente à reestruturação produtiva, tomando-se, como eixo, a divisão sexual do trabalho e as rel ações de gênero. Para isso, em um primei ro momento, emprega-se o paradigma da transversalidade. Posteri ormente discutem-se as atuais tendências de aumento do trabal ho feminino, de sua incorporação pelas empresas multinacionais nos países de tercei ro mundo, de acirramento de suas diferenças e de sua mai or vulnerabilidade diante do processo que torna precári os o emprego e o trabalho. Ao final, dois exemplos de trabal ho feminino - na indústria e no setor de educação - contribuem para a reflexão acerca dos efeitos da reestruturação produtiva na saúde da mulher trabalhadora, apontando a problemática do tempo extenso de trabalho.

Palavras-chave Trabalho Feminino; Saúde da Mulher; Saúde Ocupacional; Relações de Gênero 
Introdução

Com este texto tem-se por objetivo contribuir com os estudos e as ações associadas à saúde dos trabal hadores e trabal hadoras, desenvolvendo uma análise que toma os conceitos de relações de gênero e de divisão sexual do trabalho como referência. A saúde é expressão de condições sociais, culturais e históricas das coletividades em que o trabalho desempenha papel crucial. O trabalho realizado em nossa sociedade é determinado por complexo entrelaçamento de relações de poder, sociais, econômicas e políticas. Nesse momento de globalização e reestruturação produtiva, aumenta a necessidade de dar um passo na apreensão da realidade vivida pelos (as) trabalhadores (as) não só no ambiente interno de trabalho, como também em seu cotidiano, nos locais de convívio e moradia, ampliando o leque de interrogações e incorporando enfoques que colaborem para a apreensão das desigual dades e heterogeneidades produzidas. Os estudos concernentes à divisão sexual do trabal ho e às relações de gênero se inserem nesta perspectiva. Propõese que esses conceitos sejam assimilados nas análises que enfocam saúde e trabalho, em virtude de sua capacidade de trazer à tona problemas coletivos que permanecem ocultos quando as diferenças são negadas.

Por intermédio de Borderías \& Carrasco (1994) pode-se percorrer o itinerário seguido pelos estudos concernentes ao "trabalho da mulher" nas últimas quatro décadas, contextualizando a construção das análises das relações de gênero e da divisão sexual do trabalho. As autoras sinalizam que os estudos das décadas de 60/ 70 acerca do trabal ho das mulheres estavam calcados na abordagem da condição feminina - pensada em termos de especificidade - e dos papéis sexuais - analisados como complementaridade de posições sociais -, não evidenciando o caráter relacional. Nos anos 70/ 80, a reflexão a partir do ponto de vista da divisão sexual do trabalho e das relações de gênero promove verdadeira inversão nessas formas de apreensão, chamando a atenção para a necessidade de entender as relações de trabaIho não apenas na esfera econômica, mas levando ao questionamento dos conceitos sociológicos. É nesse sentido que Kergoat desnaturaliza o conceito de qualificação, mostrando que as operárias são adequadamente qualificadas por meio do trabalho doméstico para as funções que exercem na indústria, sem que esse processo informal de qualificação seja reconhecido. Essa nova orientação da análise das especificidades das práticas e culturas femini- nas tende a privilegiar a subjetividade e as inter-relações produção-reprodução, caminhando para o paradigma da transversalidade das relações sociais de sexo.

A necessidade de questionamento "transversal" é colocada por Pitrou (1979, apud DauneRichard \& Devreux, 1990) no final da década de 1980, quando aponta a questão da dinâmica do sistema social global, enunciando as imbricações entre o sistema de produção e o sistema familiar. Kergoat (1996), em artigo do mesmo período, parte de uma crítica à "sociologia da dominação" e propõe a construção de uma "sociologia das relações de sexo", frisando que a divisão técnica e social do trabalho se justapõe à divisão sexual do trabalho. Segundo esse autor, a definição de relações sociais de sexo repousa em ruptura radical com as explicações biologizantes das diferenças entre as práticas sociais masculinas e femininas e a divisão do trabalho entre os sexos, que é ponto fundamental nessas relações. Isso significa que "a relação entre os sexos não se esgota na vida conjugal, maséativa no lugar do trabal ho, enquanto que a rel ação de classes não se esgota no lugar do trabalho, mas é ativa, por exemplo, na relação com o corpo ou na relação com as crianças" (Kergoat, 1996:22-23).

No que se refere ao trabalho doméstico, Borderías \& Carrasco (1994) observam que a maioria das disciplinas o tem ignorado como objeto de investigação, indicando os estudos dos anos 60 como precedentes quanto a problemas de inadaptação e estresse das donas de casa norte-americanas, relativos ao isolamento, à falta de estímulos, às relações de poder e dependência e suas conseqüências no bem-estar. Ainda nos anos 60 emerge a polêmica a respeito da natureza do trabalho doméstico, na qual esteve em questão a harmonia dos interesses femininos e masculinos defendida pelos marxistas, que apontavam o capitalismo como único beneficiário do trabalho doméstico. Ao final dos anos 70, os estudos concernentes às transformações do trabalho doméstico nas sociedades de consumo - de trabalho estritamente reprodutivo para trabal ho relacional implicaram a necessidade de revisão de categorias analíticas que pudessem dar conta das novas complexidades, destacando-se o conceito de "trabalho familiar". Refletindo tendências mais recentes de construção de objetos transversais, o conceito de "carga mental" foi cunhado para dar conta da atividade de gestão dos espaços e tempos que está presente no trabalho não remunerado e que também é exigência da conciliação de funções relativas ao trabal ho remunerado e não remunerado. 
Essa introdução sinaliza a perspectiva de refletir acerca da temática saúde e reestruturação produtiva, referenciando-se em conceito ampliado de trabalho - que abrange o trabalho doméstico - e suas interações com a reprodução social e os modos de vida. Repousa também na apreensão de que a saúde é resultante de relações sociais, de classe e de sexo.

Cabe ressaltar que, no âmbito de estudos específicos da relação saúde/ trabalho, a emergência, nos últimos anos, do olhar sobre a muIher trabalhadora tem evidenciado a impossibilidade de separar, analítica e concretamente, os espaços de trabalho e de consumo, o trabaIho e o descanso, o trabalho remunerado e não remunerado, apontando novos temas de pesquisa (Noriega, 1995).

Neste artigo vai-se discutir primeiramente o cenário geral do trabalho das mulheres frente à reestruturação produtiva sob o ponto de vista da saúde coletiva. Posteriormente, procurarse-á articular essa análise com questões descortinadas em dois estudos de casos, desenvolvidos no Rio de Janeiro, com operárias da indústria química e com profissionais de educação. Com isso, espera-se fornecer elementos para dar concretude à revisão teórica efetuada anteriormente, contudo sem estender cada um dos casos. Trata-se, então, de um caminho de elaboração teórica, em que se procura dar sentido a um conjunto de questões aparentemente dissociadas, com vistas à compreensão da dinâmica em curso e seus reflexos na saúde segundo perspectiva de gênero.

\section{Tendências atuais}

Consultando diferentes autores pode-se apontar resumidamente as seguintes tendências mundiais:

- a incorporação de elevada proporção de mulheres em processos produtivos instalados, por empresas multinacionais, em qualquer lugar do planeta onde o custo de produção seja menor e sua conseqüente proletarização (Benería, 1994);

- a tendência de acirramento da diversidade e heterogeneidade das situações de trabal ho dos homens e mulheres tanto em países do Sul como do Norte (Hirata, 1997)

- o aumento crescente do trabalho feminino e a maior vulnerabilidade das trabalhadoras frente à precarização do trabal ho (Armstrong, 1995; Antunes, 1997; Hirata, 1997), processo que se reflete seja no aumento do setor informal seja nas modalidades de emprego baseadas em contratos temporários ou em outros regimes atípicos.
A geografia do produção, a saúde

e as relações de gênero

A mobilidade do capital em direção aos países do Terceiro Mundo - principal característica da divisão do trabal ho que avança nos anos 80 - é paralelamente seguida pela tendência de concentração do capital nas empresas multinacionais. A forma como isto ocorre é, porém, bastante seletiva, na medida em que não se constata a intensificação esperada do fluxo de capital entre o Centro e a Periferia, podendo-se faIar em desconexão forçada entre Norte e Sul (Coutrot \& Husson, 1993). Por esse motivo, Coutrot \& Husson (1993) salientam que a reestruturação produtiva é acompanhada da reconstituição, sob nova forma, da divisão do mundo entre Centro e Periferia, criando nova base de dependência. Ao Terceiro Mundo está destinado um papel determinado pelas exigências de crescimento dos países mais industrializados, levando a rigorosa seleção das regiões e setores mais suscetíveis de fazer parte dessa dinâmica, abolindo-se a maior parte da espécie humana desse processo. Neste contexto são instauradas novas formas de concorrência, nas quais a melhor formação da mão de obra, a qualidade, a inovação e a velocidade de resposta à demanda tornam-se determinantes da produção e de seu ambiente sócio-institucional em detrimento do fator salário.

Contudo, quando ao capital interessa organizar a produção internacional, tirando vantagem dos baixos salários e da fraca regulamentação do trabal ho existentes em países do Terceiro Mundo, há a tendência de as mulheres serem a força de trabalho preferida.

A transferência do trabalho intensivo de indústrias têxtil, de confecção, de brinquedos e de componentes eletrônicos dos países mais industrializados - sobretudo os Estados Unidos, a Europa Ocidental e o Japão - foi feita, em uma primeira fase, para países do sudeste asiático e de outros, tais como Il has Maurício, Chipre e zonas do Brasil e do México. Em uma segunda fase, atingiu a Índia, Indonésia, Tailândia e al guns países latino-americanos - como a República Dominicana e El Salvador - e, mais recentemente, a China. A busca do lugar e do processo de produção mais barato em qualquer região do planeta levou ao que se tem qualificado de "nova preferência pelo emprego das mulheres" e, por sua vez, a sua proletarização (Benería, 1994).

O fenômeno das zonas francas é exemplo ilustrativo dessa forma de incorporação das mulheres na nova divisão internacional do trabalho. Criadas para atrair capital estrangeiro, 
essas zonas industriais de países de terceiro mundo empregam grande parcela de mulheres jovens, solteiras e com alto nível de educação. Outros exemplos são dados por Antunes (1997), como a produção de tênis Nike na Indonésia, que emprega mul heres recebendo US\$38 por mês, com jornada de 60 horas semanais, enquanto em Bangladesh, para idêntica jornada, o salário não chega a US\$30.

Uma contribuição importante para a análise da divisão internacional e sexual do trabaIho é feita por Le Doaré (1984). A autora mostra que a exportação de parcela do processo de produção por meio da terceirização em escala mundial ocorre simultaneamente à transferência das modalidades de divisão sexual dos países dominantes para os periféricos. A terceirização ao nível internacional corresponde a processo de replicação da dominação das muIheres, pois o que é exportado e explorado é o caráter tradicionalmente desvalorizado do trabalho feminino.

Certamente, esse é um dos fatores explicativos das "persistências, continuidades e similaridades" existentes na divisão sexual do trabalho em países que ocupam posições contrastantes no cenário da divisão internacional do trabalho e no nível de desenvolvimento econômico e tecnológico (Hirata, 1993). Tanto nos países centrais quanto nos periféricos, os métodos e técnicas tayloristas são aplicados majoritariamente às mulheres, ao passo que a gestão taylorista é predominante nas fábricas em que é grande o número de operárias. A divisão sexual do trabalho atravessa a reestruturação produtiva, implicando a coexistência de um setor flexibilizado masculino e de um setor taylorizado feminino (Kergoat, 1992). De fato, as comparações internacionais referentes à divisão sexual do trabalho têm sido importantes para evidenciar que os modelos teóricos utilizados na análise da restruturação produtiva estão referenciados a determinado arquétipo de trabalhador qualificado e polivalente (Hirata, 1994), uma vez que, na outra extremidade, o taylorismo continua sendo prevalente nos setores de produção que mais empregam mulheres, as quais até aqui não têm sido requalificadas para os novos equipamentos de base microeletrônica. A persistência da divisão sexual do trabalho é claramente demonstrada, para o caso da França, quando as conclusões alcançadas pelo trabalho pioneiro de Madeleine Guilbert, desenvolvido em 1966 (Guilbert, 1966), são reafirmadas pela pesquisa realizada por Danièle Kergoat, em 1982 (Kergoat, 1982), e pelas subseqüentes análises estatísticas do Ministério do Trabalho desse país no ano de 1993
(DARES, 1993): o trabalho das mulheres nas indústrias é caracterizado pela repetitividade, monotonia e pelo ritmo intenso. No que se refere ao Brasil, a reorganização produtiva é ainda marginal e pouco significativa, identificando-se a emergência de novos modelos de organização do trabal ho nas grandes empresas, de setores competitivos da economia e que empregam mão-de-obra masculina (Hirata, 1993).

No entanto, cabe aqui também apresentar uma reflexão de Armstrong (1995) a respeito do que tem significado a feminização da força de trabalho com base em dados do Canadá. Sua análise indica um movimento simultâneo e distinto do que foi exposto acima, que parece estar ocorrendo nesta complexa roda viva. A globalização tem eliminado alguns dos empregos masculinos e alterado os postos tradicionalmente ocupados por homens, fazendo com que estes se aproximem dos femininos, em particular, quanto à precariedade. Para a autora, o trabalho de mulheres e homens tem se tornado similar em virtude de que menor número de pessoas de ambos os sexos têm conseguido escolher o tipo de trabalho que desejam realizar, restando assumir postos não valorizados.

Para entender o que representam estes movimentos contraditórios na saúde das trabal hadoras e trabal hadores lembrar-se-á Berlinguer (1980), que salienta: “no plano sanitário énotório quea maior freqüência de distúrbios edoenças profissionais ocorrem entre as categorias menos qualificadas" (Berlinguer, 1980:6). Outros autores mostraram igualmente que as doenças associadas ao trabalho das mulheres neste quadro de divisão social do trabalho caracterizam-se por serem do tipo insidioso, muitas vezes inespecíficas e não indenizáveis (Volkoff, 1985), inexistindo normas apropriadas às condições do trabalho feminino. Para Frigul et al. (1993), as mulheres encontram-se inseridas nos ângulos mortos do sistema previdenciário com a acumulação de agravos não específicos. É considerando esta dificuldade de apreender os riscos do trabalho das mulheres que Messing et al. (1997) sustentam que, para analisar os aspectos físicos do trabalho feminino, é necessário tomar em conta o somatório de esforços realizados durante uma jornada, a qual, em muitos casos, é superior a um único esforço não repetitivo referente a uma atividade masculina. Esses autores mostraram que o trabalho leve das mulheres as expõem a posturas forçadas, com relação às quais não há critérios para estabelecer limites.

Associa-se também às funções repetitivas e que exigem cadência el evada e postura estática - desempenhadas majoritariamente por mu- 
Iheres na indústria e que se intensificaram com a introdução das novas formas de organização do trabalho - o conjunto de lesões osteoarticulares, as quais incluem distúrbios que atingem dedos, punhos, antebraços, cotovelos, ombros, pescoço e regiões escapulares; resultantes do desgaste muscular, tendinoso, articular e neurológico. Observa-se que a incidência dessas lesões, cuja nomenclatura é bastante diversificada entre os países, está relacionada, além de a fatores etiológicos - exigências físicas e mentais do trabal ho -, a fatores agravantes, como a forma de organização do trabalho - o número excessivo de horas trabalhadas e o ritmo de trabalho -, a insuficiência de repouso e relaxamento - importante no caso das mulheres, tendo-se em vista a alternância trabal ho assalariado e doméstico - e a certas predisposições individuais - idade, estado geral de saúde, força muscular, habilidade profissional etc.-, que não devem ser enfatizadas em detrimento de outros fatores (Ono et al., 1987).

Sob o ponto de vista da psicossomática, entende-se que a ausência de significado dos movimentos realizados nos trabalhos repetitivos não pode deixar de representar fonte de patologia. Esses movimentos seguem ritmos que foram interiorizados pelas mulheres desde a infância, levando-as a manter o aparel ho motor em hiperatividade. Ou seja, o aparelho motor é utilizado como sistema de defesa privilegiado (Peze, 1997). Nessa relação de escravidão que as trabalhadoras mantêm com o tempo é que se desenvolvem - e se realimentam - as atividades do trabalho repetitivo.

Cabe sinalizar que as lesões por esforços repetitivos estão também fortemente associadas às atividades de processamento de informações, sobretudo a entrada e manipulação de dados, cuja mão de obra empregada é principalmente feminina. Com a tecnologia das telecomunicações, essas atividades têm sido organizadas sob o regime da subcontratação ou mesmo internacionalizadas mediante a transferência para os países periféricos. Se as lesões por esforços repetitivos, a deterioração da capacidade visual, o estresse e a fadiga, as dermatoses e os problemas reprodutivos são apontados como conseqüências, em geral, dessas atividades (Pearson, 1995), o estudo específico de Soares (1992), a respeito de teletrabalho e comunicação em centros de processamentos de dados, no Brasil, indica que o isolamento social é seu aspecto mais problemático. Para o autor, a imposição cultural de que as mulheres sejam responsáveis pela socialização das crianças contribui para que o teletrabalho seja amplamente feminizado. E, embora um dos prin- cipais argumentos para sua expansão seja a possibilidade de conciliação com trabalho doméstico, Vedel \& Gunnarsson (1985, apud Soares, 1992) ressaltam que os períodos de pique dessas atividades coincidem com os momentos em que as mulheres deveriam estar à disposição das crianças, sugerindo que o teletrabalho interfere diretamente nos relacionamentos familiares. No que se refere ao isolamento, um de seus efeitos é a desorganização emocional dos(as) trabalhadores(as) e a dificuldade ou impossibilidade de constituição, através da identificação com o outro, de grupos informais; grupos de resistência e de defesa da saúde e da vida.

De fato, conforme Lerolle (1995), as modernizações técnicas e organizacionais não são simplesmente melhorias de eficácia, mas se remetem diretamente às relações de trabal ho anteriormente construídas. A autora procura mostrar a importância da vitalidade dos coletivos de trabalho para a (re)construção da saúde diante das mudanças organizacionais, que se caracterizam: pelo desconhecimento dos valores e regras de trabal ho nos quais repousam os coletivos; pela destruição do equilíbrio anteriormente conquistado pelos(as) trabalhadores(as) e por grande dificuldade de instaurar um debate relacionado aos riscos dessas mudanças. Refletindo acerca de suas experiências de intervenção, Lerolle (1995) sinaliza que a aceitação da modernização produtiva por parte dos(as) trabalhadores(as) e a preservação da saúde dependem da possibilidade de reconstrução de valores e do sentido do trabalho nos quais se apoiam o desenvolvimento das identidades subjetivas e coletivas. O autor destaca a contradição entre os discursos que valorizam a autonomia e a ausência de meios para exercê-la efetivamente, citando o exemplo das operárias de uma confecção que foram organizadas, de forma autoritária e sob forte exigência de produção, em "grupos autônomos" e restabeleceram rapidamente a mesma divisão do trabalho taylorizada anterior. Diante de tantas pressões, essa era a solução menos desgastaste para elas. Lerolle (1995) chama a atenção para o fato de que o trabal ho individualizado e a precarização tornam difícil a estruturação de coletivos e que, no caso das mulheres, seus valores/regras são muito distantes daqueles impostos pela gerência e mesmo daqueles defendidos por organismos sindicais, o que dificulta a configuração de forma de resistência aberta/ explícita. 
Gênero, precarização e pobreza

O status geopolítico, além da idade, classe, raça e preferência sexual, étalvez o fator mais determinante de diferenças nas experiências femininas (Doyal, 1995). Assim, tem-se que 2/ 3 das mulheres vivem em países de terceiro mundo, onde a renda per capita é baixa e a expectativa de vida pequena, as taxas de fertilidade são altas e a percentagem de mulheres no mercado é relativamente menor. Esses países, nos quais é acentuada a desigualdade no nível de renda segundo as classes sociais, compartilham a experiência do colonialismo e imperialismo, resultando em graus variados de subordinação.

Segundo dados do Relatório de Desenvolvimento Humano, da Organização das Nações Unidas (ONU , 1995), as mulheres de todas as regiões do mundo são responsáveis por $53 \%$ do trabalho total (remunerado e não remunerado) nos países em desenvolvimento e $51 \%$ nos países industrializados; cerca de 2/ 3 do trabalho feminino são atividades não-remuneradas e a carga horária diária do trabalho da mulher é, em média, 13\% maior que a dos homens. Com a precarização do trabalho decorrente da globalização da economia, elas se encontram também nas situações mais vulneráveis. Conforme enfatiza Vincent (1994), há uma forma de flexibilização que está ligada à formação e re-qualificação dos trabalhadores, mas a flexibilidade mais praticada na maior parte dos países ocidentais é aquela da precarização do emprego e do desemprego.

$\mathrm{N}$ a verdade, a precariedade sempre esteve associada ao trabalho feminino, uma vez que, mesmo quando a insegurança, a instabilidade e o desemprego atingem toda a população de trabalhadores, o trabalho masculino tende a estabilizar-se, enquanto que o feminino tende a manter-se incerto e irregular. Para Frader (1997), é a desvalorização do trabalho feminino seja nos discursos e representações seja nas estruturas econômicas - mediante a organização sexuada do mercado de trabalho - a causa de sua precariedade. A precarização pode ser definida de maneira descritiva tanto em relação às novas formas de emprego, designadas como atípicas, quanto em relação às condições de trabalho em função do enfraquecimento ou perda de direitos sociais, sindicais, de prevenção e de reparação dos riscos. Inclui o trabaIho a domicílio, a terceirização, o trabal ho em tempo parcial, o trabalho informal, os contratos temporários, o trabalho sazonal, mas também designa aqueles nos quais a organização é rígida e é intenso o sofrimento físico e mental (Thébaud-Mony, 1994). Contudo, alguns auto- res (Huez, 1994) propõem-se a definir a precarização a partir do indivíduo. Para eles, a precariedade é aquilo que diminui as margens de possibilidades de construção da saúde e identidade, aquilo que entreva essa construção.

No Brasil e demais países da América Latina é significativa a presença de mulheres no setor informal, onde trabalham sem proteção trabalhista, sem carteira assinada, com tempo prolongado, executando as atividades nas ruas ou a domicílio. Em 1995, cerca de 30\% das assalariadas eram trabalhadoras domésticas, representando quase $17 \%$ da ocupação das muIheres. Outras $16,6 \%$ encontravam-se na categoria de trabalho por conta própria, enquanto 13\% trabalhavam sem remuneração financeira. Outras 9\% permaneciam nas atividades de subsistência, produzindo para consumo próprio, sem estarem incorporadas ao mercado de trabal ho formal ou informal. No ano de 1995 , segundo dados do IBGE, trabal havam sem carteira de trabal ho assinada $54 \%$ das mulheres assalariadas, excluídas as funcionárias públicas e militares. Neste contingente estão incluídas as empregadas domésticas: somente 2,7\% dos trabalhadores desta categoria têm registro em carteira (DIEESE, 1998).

Estudos concernentes ao trabal ho temporário, realizados no Chile, alertaram para a problemática da saúde mental: trabalhadoras da indústria da pesca e de fruticultura sinalizaram que a condição de eventualidade gera temor e ansiedade (Díaz \& Medel, 1997). No trabalho a domicílio não há distinção entre espaços de produção e reprodução, uma vez que ambos implicam demandas de energia e ambos geram compensações (Acevedo, 1997). No Chile, as mulheres que trabalham a domicílio para a indústria de confecção dedicam o mesmo tempo de trabalho que as trabalhadoras que exercem tal função na própria fábrica, porém sua jornada se prolonga até tarde da noite, depois das 20hs, quando as demandas familiares e domésticas começam a reduzir (Díaz \& Medel, 1997). Cabe dizer que as situações de demanda constante de trabalho sem períodos de descanso, levam à permanência de níveis constantes dos hormônios de adaptação, o que resulta em alteração das fases do sono e da profundidade do descanso noturno (Valls-Llobet, 1997). Outra conseqüência é a sensação de cansaço matutino, com alterações no ritmo cardíaco, ansiedade, angústia e aumento da contratura muscular, proporcionando dores nas zonas cervical, dorsal e lombar.

A precarização é processo que se articula com a pobreza, que vem crescendo mesmo nos países industrializados. As mulheres represen- 
tam $70 \%$ do 1,3 bilhão de pessoas que vivem em condições de pobreza absoluta no mundo. O conceito de feminização da pobreza procura explicitar a grande presença de mulheres entre os pobres, seu aumento progressivo e os condicionantes dessa realidade (Anderson, 1994). Esse conceito foi introduzido pela primeira vez em 1978, nos Estados Unidos. Estudos na África mostraram a persistência de quatro grupos entre a população pobre: os órfãos, os que estão física e mentalmente incapacitados, as viúvas e os velhos, que são representados, com maior freqüência, pelas mulheres em função da sobrevida feminina. No Brasil, $20 \%$ das famílias é chefiada por mulheres. As que trabaIham por conta própria chegam a ficar até 14 horas vendendo na rua ou em casa e colocam seus filhos para ajudá-las ou substituí-las nas tarefas domésticas.

Outros fatores que interferem no quadro de pobreza e de precarização, segundo Anderson (1994), são os ativos sociais - todos os salários, bens e serviços a que tem acesso um indivíduo através de seus vínculos sociais - e os ativos culturais - educação formal e conhecimento cultural que permite um indivíduo desenvolver-se em seu ambiente - de que se dispõe. Algumas análises destacaram que a liberdade masculina para deslocar-se contribui para que os homens estabeleçam vínculos com ampla variedade de indivíduos, grupos e associações, assim como para que aprendam os procedimentos formais e informais para lidar com instituições e com a burocracia pública ao acumular ativos culturais.

Destaca-se também que as mulheres realizam grande quantidade de trabalho não pago, não só o chamado trabalho doméstico, mas também o trabalho de cuidar da família, que apresentam componentes emocionais importantes e que consomem muito tempo. Esse fato deve ser analisado pela sua importância na reprodução do quadro de pobreza e precariedade das mulheres.

\section{Configurações específicas da} relação gênero, saúde e trabalho no contexto de reestruturação produtiva e globalização

Ao realizar um estudo relativo à saúde das operárias de indústrias químicas localizadas no subúrbio do Rio de Janeiro, a tendência encontrada de emprego de mão de obra feminina nos estabelecimentos de menor porte - empresas de "fundo de quintal" - despertou a atenção, parecendo ser esse um aspecto concreto da transversali dade das relações sociais de sexo. Nessas empresas - sejam fábricas de produtos de plásticos sejam laboratórios farmacêuticos - as condições de trabal ho são precárias, persistindo inclusive o uso de maquinários tradicionais. A informalidade das relações sociais de trabalho presente nesses estabelecimentos torna mais difícil para os(as) trabalhadores(as) a recusa de trabalhar em situação de risco. Por um lado, problemas alérgicos, respiratórios, renais, ginecológicos, dermatológicos e de coluna foram mencionados com freqüência pelas operárias. Por outro lado, elas mostraram perceber a relação entre a saúde e o trabalho de forma inespecífica, citando como resultantes do processo de trabalho: esgotamento físico, nervosismo e problemas visuais. É importante salientar que entram em contato direto com substâncias químicas e outros riscos nas atividades manuais e periféricas que realizam em função da divisão sexual do trabalho, em particular, nos pequenos laboratórios farmacêuticos. A precariedade de suas condições de trabalho é agravada por serem muitas vezes subcontratadas pelas chamadas agências de emprego - modalidade aplicada à mão de obra feminina já há muito tempo no Brasil e que não é alterada com a reestruturação produtiva.

Pode-se perceber, através desses elementos, a reprodução do cenário descrito anteriormente:

- a permanência da divisão sexual do trabaIho (as trabalhadoras que ocupam os postos taylorizados, repetitivos e "desqualificados");

- a invisibilidade dos riscos e agravos que acometem essas trabal hadoras (os organismos de vigilância à saúde raramente atuam nessas empresas; o processo crônico de adoecimento não chega normalmente a emergir);

- as relações de trabal ho existentes dificultam a estruturação de um coletivo capaz de resistir abertamente às pressões/ condições de trabalho.

O valor do trabalho dessas mulheres, expresso nos baixos salários que recebem (entre 1,5 e 3,8 salários mínimos), representa custo particularmente elevado para a saúde das chefes defamília, de quem podem depender várias pessoas, entre filhos, irmãos, mães e companheiros desempregados. Em algumas situações, as trabalhadoras são forçadas a desempenhar atividades remuneradas ininterruptas, sem tempo para descanso, emendando a jornada na fábrica com a jornada em atividade informal

Quando se desloca o foco para outro setor da economia - a educação -, os problemas de saúde coletiva relacionados à reestruturação 
produtiva neoliberal ganham contornos diferentes e, ao nosso ver, ainda mais obscuros. No caso do Brasil, o sistema educacional público tem sido levado a um quadro de precarização e degradação em que, paradoxalmente, sua produtividade encontra-se na improdutividade (Frigoto, 1984). O quadro de sucateamento das escolas públicas revela-se no abandono dos equipamentos e instalações, assim como na crescente depreciação dos (das) trabalhadores (as) via rebaixamento salarial e precárias condições para a realização de suas atividades. Neste mesmo movimento, importou-se a óptica empresarial e seu discurso gerencial para a Escola Pública, com "novas" propostas e experiências racionalizadoras, como a da terceirização de algumas funções. Se ocorreu, em um primeiro momento, a drástica redução com gastos em educação, em um segundo momento tende a emergir (Salm, 1991) a revalorização da escolaridade, com a introdução de novas técnicas e tecnologias que alteram o conteúdo e a forma de trabalho, inclusive da organização de trabalho.

Em pesquisa desenvolvida junto com o Sindicato Estadual dos Profissionais de Educação (SEPE-RJ), dirigida a uma parcela feminizada de educadores cuja presença quase invisível contrasta com a importância social do trabaIho que realizam - as merendeiras e serventes -, percebe-se quão incompleta permanecem as análises relativas ao tema que têm privilegiado o setor industrial com mão de obra majoritariamente masculina. Essas análises, que muitas vezes se baseiam em estudos de caso relativos às mudanças ocorridas em grande empresa, mostram a tendência, não universal, de flexibilização/modernização de processos produtivos, deixando em aberto mundos de trabalho precarizados.

No entanto, um contingente de mais de 10.000 merendeiras e serventes - atomizado em mais de 3.000 escolas públicas existentes no Rio de Janeiro - percebe a degradação de suas condições de trabal ho e de vida decorrentes da nova ordem econômica e produtiva. Com a redução do número de merendeiras e serventes em cada escola, somada ao tempo exíguo para a realização de suas atividades e à fal ta de investimentos em instalações e equipamentos nesses ambientes de trabalho, a sobrecarga gerada tem acarretado o adoecimento de número relevante de trabalhadoras. Destaca-se que a maioria delas também complementa a remuneração por intermédio de uma terceira jornada no mercado informal. As queixas relativas às lesões por esforços repetitivos, às doenças do coração e aos problemas de saúde mental - tensão, irritabilidade, insônia etc. - estão fortemente relacionadas às condições precárias de trabalho. São indicadores desse quadro as readaptações freqüentes entre esses(as) trabalhadores(as) por motivo de saúde. Sem condições de permanecer no desempenho das mesmas atividades ou de continuar realizando-as com a mesma intensidade, estes são colocados em readaptação pelo serviço de perícia - embora tal readaptação não ocorra de fato, na medida em que raramente há redução de carga de trabalho. Conforme levantamento feito, utilizando dados relativos ao período de 1993 a 1997 da Superintendência de Saúde Ocupacional do Estado, o número de readaptações para o conjunto dos educadores (as) cresceu $50 \%$ durante o período. Entende-se que semelhante incremento é o reflexo de processo de deterioração das condições de trabalho e de vida desses (as) trabaIhadores (as), que se manifesta em desprazer e em patologias.

\section{Considerações Finais}

Neste artigo procura-se apresentar alguns elementos que contribuem com a reflexão acerca das relações de gênero, da saúde e da reestruturação produtiva, indicando suas diversas articulações e possibilidades de abordagens. Ao final, procura-se dar concretude à discussão por meio de exemplos, um referente ao trabaIho industrial e outro ao trabalho em escolas públicas, onde questões similares foram evidenciadas. O setor industrial tem sido objeto privilegiado de estudos concernentes à reestruturação produtiva e de investigações no campo da saúde do trabalhador. Entretanto, esses estudos são limitados no que tange a mostrar a heterogeneidade de processos produtivos existentes no Brasil ao tratarem de casos específicos, normalmente indústrias de ponta e com perfil masculino de mão de obra. Por intermédio do exemplo do trabalho de muIheres na indústria química indica-se a persistência de processos de trabalho taylorizados e sua precariedade. Ao analisar o que vem ocorrendo com as trabalhadoras da indústria e da educação, observa-se que a forma de precarização de trabalho nos dois casos é aquela sinalizada pela presença simultânea dessas mulheres no setor formal e informal e, consequentemente, pelo emprego de grande parte do tempo cotidiano em atividades de trabalho. A divisão sexual do trabalho, produzida pela organização do trabalho, impõe-Ihes jornada ilimitada, a qual, associada ao trabalho familiar e aos 
menores recursos de que dispõem, representa esforço excessivo, podendo contribuir para a deterioração progressiva da saúde dessas muIheres (Acevedo, 1997), incluindo problemas ligados à saúde mental. As relações sociais de sexo implicam, ao mesmo tempo, uma sobrecarga no trabalho doméstico e uma sobrecarga no trabalho remunerado.

Esta análise mostra a importância das noções de trabalho remunerado - e não apenas "trabalho assalariado", uma vez que o trabalho formal e o informal não são excludentes - e tra- balho não remunerado para a apreensão do conjunto de atividades desempenhadas pelas trabalhadoras. Isso significa que não basta considerar a inserção formal das mulheres no trabalho - quando existe - para analisar a situação de saúde e doença. Aponta também a problemática do tempo extenso de trabal ho e seus efeitos no quadro de saúde das mulheres pobres de países como o Brasil. Quando se trata de mulheres, o tempo de trabalho parece ser elemento importante para tornar visível a dinâmica saúde-trabal ho em transformação.

\section{Referências}

ACEVEDO, D., 1997. Género y flexibilización del trabajo: I mpacto en la salud. Cuadernos Mujer Salud, 2:28-36.

ANDERSON, J., 1994. La feminización dela pobreza en América Latina. Lima: Red Entre Mujeres. Diálogo Sur-Norte.

ANTUNES, R., 1997. A lógica do capital. Dossiê Globalização: Globalização, Tecnologia e Relações de Trabalho (J. Gorender). Estudos Avançados, 11: 311-391.

ARMSTRONG, P., 1995. The feminization of the labour force: Harmonizing down in a global economy. In: Invisible: La Santé des Travailleuses (K. Messing, B. Neis \& L. Dumais, eds. ), pp. 368-392, Charlottetown: Gynergy Books.

BENERIA, L., 1994. Mujer, salud y trabajo: Una visión global. Quadern CAPS, 21:7-16.

BERLINGUER, G., 1980. A Mulher ea Saúde. Jornalivro Série: Cadernos da Mulher. São Paulo: CEBES.

BORDERIAS, C. \& CARRASCO, C., 1994. Las mujeres y el trabajo: Aproximaciones históricas, sociológicas y económicas. In: Las Mujeres y el Trabajo: Rupturas Conceptuales (C. Borderías, C. Carrasco \& C. Alemany, eds.), pp. 15-109, Barcelona: Icaria - Suhem.

COUTROT, T. \& HUSSON, M., 1993. Les Destins du Tiers Monde: Analyse, Bilan et Perspective. Luçon: Éditions Nathan.

DARES (Direction de l'Animation, de la Recherche, des Études et des Statistiques), 1993. Conditions, Organisation du Travail et Nouvelles Tecnologies en 1991. Résultats del'Enquête Conditions de Travail. Paris: DARES.

DAUNE-RICHARD, A. M. \& DEVREUX, A. M., 1990. La reproduction des rapports sociaux de sexe. In: À Propos des Rapports Sociaux de Sexe (F. BattaglioIa, D. Combes, A. M. Daune-Richard, A. M. Devreux, M. Ferrand \& A. Langevin, eds.), pp.117234, Paris: Centre de Sociologie Urbaine/ CNRS.
DIAZ, X. \& MEDEL, J., 1997. Mujer, trabajo y salud: Los daños ocultos. Cuadernos Mujer Salud, 2:37-46.

DIEESE (Departamento Intersindical de Estudos Estatísticos e Sócio-econômicos), 1998. Eqüidade de Gênero nas Negociações Col etivas. Cláusulas Relativas ao Trabalho da Mulher no Brasil, 29 novembro 1998 ঝttp:// www.dieese.org.br/esp/ eslout97.html>.

DOYAL, L., 1995. What Makes Women Sick: Gender and the Political Economy of Health. London: Macmillian Press Ltd.

FRADER, L., 1997. Précarité du travail et rapports sociaux du sexe: Une perspective historique. In: Précarisation Sociale, Travail et Santé (B. Appay \& A. Thébaud-Mony, eds.), pp. 293-312, Paris: IRESCO.

FRIGOTO, G., 1984. A Produtividade da Escola Improdutiva. São Paulo: Cortez Editora/ Autores Associados.

FRIGUL, N.; BRETIN, H.; METENIER, I.; AUSSEL, L. \& THEBAUD-M ONY, A., 1993. Atteintes à la santé et exclusion professionnelle. Travail et Emploi, 56: 34-44.

GUILBERT, M., 1996. Les Fonctions des Femmes dans I'Industrie. Paris: Mouton.

HIRATA, H., 1993. Division sexuelle du travail et internationale du travail. Futur Antérieur, 16:27-40.

HIRATA, H., 1994. Rapports Sociaux de Sexe et Division du Travail: Contribution à la Discussion sur le Concept de Travail. Paris: Centre National de Recherche Scientifique. (mimeo.)

HIRATA, H., 1997. Globalização, trabal ho e tecnologias: Uma perspectiva de gênero. In: 8o Encontro Internacional Mulher e Saúde, Resumos, p. 3. Rio de Janeiro: Rede Nacional Feminista de Saúde e Direitos Reprodutivos.

HUEZ, D., 1994. Souffrances et Précarités au Travail: Paroles de Médecins du Travail. Paris: Syros.

KERGOAT, D., 1982. Les Ouvriéres. Paris: Le Sycomore. 
KERGOAT, D., 1992. Les absentes de l'histoires. Série Mutations Autrement, 126:73-83.

KERGOAT, D., 1993. Des hommes, des femmes et du travail. Education Permanente, 116:133-139.

KERGOAT, D., 1996. Relações sociais de sexo e divisão sexual do trabalho. In:. Gênero eSaúde(M. J. Lopes, D. Meyer \& V. Waldow, org.), pp. 14-27, Porto Alegre: Artes Médicas.

LE DOARÉ, H., 1984. Division sexuelle et division internationale du travail. Reflexions à partir des usines d'assemblage (Mexique-Haïti). In: Le Sexe du Travail (B. F. Barrère-Maurisson; B. Beccalli; A. Borzeix; D. Chaudaud; M. Chaudron; D. Combes; A.-M. Daune-Richard; A. M. Devreux; M. Ferrand; D. Fougeyrollas-Schwebel; L. Gitahy; M. Haicault; F. Hakiki-Talahite; H. Hirata; J. Humphrey; A. Kartchevsky-Bulport; D. Kergoat; A. Langevin; J. Laufer; H. Le Doaré; M. Maruani; R. Moyses; M. Pacífico; D. Ronci \& E. Souza-Lobo, eds.), pp. 175190, Grenoble: PUG.

LEROLLE, A. F., 1995. Mutations organisationnelles et santé au travail des femmes. Cahiers du GEDISST, 13:41-56.

MESSING, K.; SEIFERT, A. M. \& GONZALEZ, R., 1997. Haciendo visible lo invisible: Indicadores científicos de procesos nocivos que afectan la salud de las mujeres en el trabajo. Cuadernos Mujer Salud, 2:15-27.

NORIEGA, M., 1995. La realidad latinoamericana frente a los paradigmas de investigación en salud laboral. Salud de los Trabajadores, 3:4-19.

OIT (Organización Internacional del Trabajo), 1996. Impacto del ajuste estrutural en el empleo y la formación de profesores. Programa de actividades sectoriales. Revista dela OIT, 16:9-10.

ONO, Y.; HOSOKAWA, M.; MAEDA, K. \& MIYAO, M., 1987. Occupational cervico-brachial disorders (ocd) and associated back pain in Japan. In: Proccedings of the International Symposium "Work-re lated musculo-skeletal disorders", pp. 279-305, Bonn: University Hospital Eppendorf.
ONU (Organização das Nações Unidas), 1995. Human Devel opment Report 1995. «tttp:// www.undp.org/ hdr/ 1995>

PEARSON, R., 1995. Gender perspectives on health and safety in information processing: Learning from international expeirences. In: Women Encounter Technology: Changing Patterns of Employment in the Third World (S. Mitter \& S. Rowbotham, eds.), pp. 278-302, New York: Routledge.

PEZE, M., 1997. Les troubles musculo-squelettiques. Pathologie de I'usure pulsionnelle? In: Colloque International de Psychodynamique et de Psychopathologie du Travail, Actes, pp. 30-31, Paris: Conservatoire National des Arts et Métiers.

SALM, C., 1991. Textos para Discussão: Consi derações sobre as Relações entre Capital eEducação. Rio de Janeiro: Universidade Federal do Rio de Janeiro.

SOARES, A., 1992. Telework and communication in data centre processing centres in Brazil. In: Technological Innovation and Human Resourses (U. E. Gattiker, ed.), Vol. 3, pp. 118-139, New York: Walter de Gruyter.

THÉBAUD-MONY, A., 1994. La precarité moderne. Politis - La Revue, 7:31-36.

VALLS-LLOBET, C., 1997. Salud laboral y morvidad. Cuadernos Mujer Salud, 2:56-60.

VINCENT, J. M., 1994. Flexibilité du travail et plasticité humaine. Texto apresentado no seminário "La Crise du Travail". Paris: Collège International de Philosophie. (mimeo.)

VOLKOFF, S., 1985. Ouvrières: Le degré zero de l'autonomie. Les Temps Modernes, Janvier, 20-27. 